\title{
A novel recessive $P D Z D 7$ bi-allelic mutation in an Iranian family with non-syndromic hearing loss
}

\author{
Hossein Fahimi ${ }^{1}$, Samira Behroozi ${ }^{2}$, Sadaf Noavar ${ }^{2}$ and Farshid Parvini ${ }^{3^{*}}$ (D)
}

\begin{abstract}
Background: Autosomal recessive non-syndromic hearing loss (ARNSHL) is genetically and phenotypically heterogeneous with over 110 genes causally implicated in syndromic and non-syndromic hearing loss. Here, we investigate the genetic etiology of deafness in two GJB2 and GJB6 negative patients presenting with pre-lingual, progressive, severe hearing loss.

Methods: Targeted exome sequencing (TES) using Next Generation Illumina Sequencing was used to analyze the exonic and some other important genomic regions of 154 genes in the proband. Subsequently, the mutation found was confirmed by Sanger sequencing in other affected sibling and healthy family members. The possible impact of the reported mutation on the corresponding protein was also evaluated by using bioinformatics tools. Moreover, the affected patients underwent audiological and ophthalmic evaluations.

Results: TES identified a novel homozygous missense mutation c.251T>C (p.184T) in exon 3 of PDZD7 gene. In addition, segregation and phenotype-genotype correlation analysis as well as in-silico evaluations confirmed the autosomal recessive inheritance pattern and disease-causing nature of mutation found.

Conclusions: In overall, our finding could expand the pathogenic mutations spectrum and strengthens the clinical importance of the PDZD7 gene in ARNSHL patients. It can also aid to conduct genetic counseling, prenatal diagnosis and clinical management of these types of genetic disorders.
\end{abstract}

Keywords: ARNSHL, Targeted exome sequencing, PDZD7 gene, Missense mutation, Iran

\section{Background}

Hearing loss (HL) is a most common sensori-neural disorder which is clinically and genetically heterogeneous. This defect is categorized in two types, syndromic (30\%) and non-syndromic (70\%) [1]. Mutations in more than 110 genes have been listed which can cause syndromic or non-syndromic HL (https://hereditaryhearingloss.org/). Mutations of GJB2 and GJB6 genes have been reported as the most causative subjects. Nonetheless, patients who

\footnotetext{
*Correspondence: f.parvini@semnan.ac.ir

${ }^{3}$ Department of Biology, Faculty of Basic Sciences, Semnan University,

Semnan 35131-19111, Iran

Full list of author information is available at the end of the article
}

are negative for mutation in GJB2/GJB6 genes are considered as attractive subjects to investigate the genetic basis of disease. One of the recently identified genes is PDZ domain-containing 7 (PDZD7) gene (MIM *612971). The PDZD7 encodes a PDZ domain containing scaffold protein that highly expressed in hair cells of inner ear. This protein is also expressed in the cilia of photoreceptors [2, 3]. PDZ domain of PDZD7 protein is responsible for binding with other proteins such as VLGR1, WHRN, and USH2A which all are very important in development and proper function of auditory and visual systems [4]. PDZD7 is highly homologous with two proteins, harmonin and whirlin, with similar expression patterns. 
These two proteins are also scaffolding proteins that give rise to autosomal recessive non-syndromic hearing loss (ARNSHL) and Usher syndrome(USH) disorders when mutated [5-7]. Defects in these proteins can damage hearing and vision. The relevant disorders are described as different types of Usher syndrome, non-syndromic hearing loss, and non-syndromic retinitis pigmentosa (RP) [5, 8-12]. It has been shown that PDZD7 play a vital role in hearing by normal development, morphology, and function of stereo-cilia of mice ear cells $[4,7,13]$. It has been reported that dysfunction or mutations of PDZD7 results in Usher syndrome type 2 (USH2) [5] and ARNSHL $[12,14-16]$.

In short, the PDZD7 gene comprised of 16 exons located on chromosome 10 (10q24.31) which encodes PDZD7 with 1033 amino acid. PDZD7 folds in to four domains (three PDZ and one Harmonin domain). PDZ2 domains are involved in dimerization of PDZD7 and also interact with VLGR1 and WHRN [4]. Herein, we report a novel homozygous missense mutation of PDZD7 in two Iranian patients with ARNSHL and negative for GJB2 and GJB6 genes mutation. This finding can expand the genetic spectrum and detection methods of the corresponding abnormalities and help physicians to order more inclusive tests. Furthermore, such studies shows that advances in the field of next-generation sequencing allow for a more accurate and less expensive diagnosis and study of molecular basis of hearing loss $[17,18]$.

\section{Methods}

At the present research we explored the molecular mechanism of ARNSHL in two affected patients from a single family. This study was approved by the Committee of Ethics in Biomedical Researches of Islamic Azad University of Medical Sciences, IR.IAU.PS.REC.1396.91. Written informed consent was obtained from all patients and their family members who participated in this study.

\section{Patients}

The studied family is of Iranian origin located in Semnan province. The two affected individuals are included in this family with two common ancestors (Fig. 1). The proband was a 30-year-old man with autosomal ARNSHL without any vision damage. He is a product of consanguineous marriage and has a sister (23-year-old) with the same phenotype. The subjects underwent audiological and ophthalmic evaluations.

\section{Screening of GJB2 and GJB6 genes}

Blood samples were collected and genomic DNAs of the all participants were extracted from peripheral blood samples using QIAamp DNA Blood Mini Kit Cat No. 51104 (QIAGENE, Germany) according to the manufacturer's instructions. First of all, the patients were screened for most common mutation c.35delG of GJB2 gene using allele specific PCR (PCR master mix, Cat no. 180301 (Ampliqon, Denmark)). Since the patients were negative for the $35 \mathrm{delG}$ mutant allele, the entire noncoding (exon 1), coding (exon 2) and flanking intronic regions of the GJB2 gene were amplified and directly sequenced using following primers: CXF' $5^{\prime}$ CCCTCC GTAACTTTCCCAGT 3'/CXR' 5' AAAACGTTTGGT GGCAGTGG $3^{\prime}$ (607 bp) for amplification of exon 1 and CXF $5^{\prime}$ CTCCCTGTTCTGTCCTAGCT $3^{\prime} / \mathrm{CXR} 5^{\prime}$ CTC ATCCCTCTCATGCTGTC $3^{\prime}$ (809 bp) for amplification of exon 2. The PCR reactions were subjected to an initial denaturation step $95{ }^{\circ} \mathrm{C} / 10 \mathrm{~s}$, followed by 40 cycles of $95{ }^{\circ} \mathrm{C} / 30 \mathrm{~s}, 60{ }^{\circ} \mathrm{C} / 1 \mathrm{~min}$ and $72{ }^{\circ} \mathrm{C} / 30 \mathrm{~s}$. Then, based on negative results of Sanger sequencing for GJB2 gene, the patients were screened for two known deletions $\operatorname{del}(\mathrm{D} 13 \mathrm{S1830})$ and $\operatorname{del}(\mathrm{D} 13 \mathrm{S1854})$ of GJB6 gene.

\section{Targeted exome sequencing and bioinformatics analysis} Regarding to negative result for screening of GJB2 and GJB6 genes mutations, the patient II-6 (proband) was more investigated by targeted exome sequencing (TES) to enrich all exons of 154 protein-coding genes (the annotated genes causing hearing impairment in the OMIM database, please see the Additional file 1) as well as some other important genomic regions (exon-intron boundaries such as splice regions) involved in hearing. The TES performed using Agilent V.6 kit (Agilent, USA) on an Illumina platform using Illumina NextSeq500 instrument. The sequencing depth was 100X. Filtering at the first step was based on frequency. Then, intronic, upstream, downstream, 3'-UTR, 5'-UTR, intergenic and other non-coding variants were filtered. After that, synonymous mutations were also filtered. Generally, test platform examined more than $95 \%$ of the targeted regions with sensitivity of $>99 \%$. By TES test, point mutations, micro-insertions/deletions and micro-duplications (<20 bp) can be simultaneously detected. The obtained results were analyzed by open access software, namely GATK [19], BWA aligner [20], and annovar [21] as well as public databases gnomAD, ExAC, GME and Kaviar ( $\sim$ Known VARiants). Furthermore, ACMG guidelines and local population database with more than 3000 unrelated individuals (BayanGene) were utilized. Ninety healthy individuals with the same ethnicity as the studied patients were also screened for the mutation found. We used Provean, SIFT, Mutation Assessor, CADD-phred, and Polyphen software to predict the possible pathogenicity of the mutation found. To analyze the evolutionary conservation of amino acid changed, the mutated PDZD7 sequence was aligned with the GenBank reference sequence (NM_001195263) and its orthologs from 


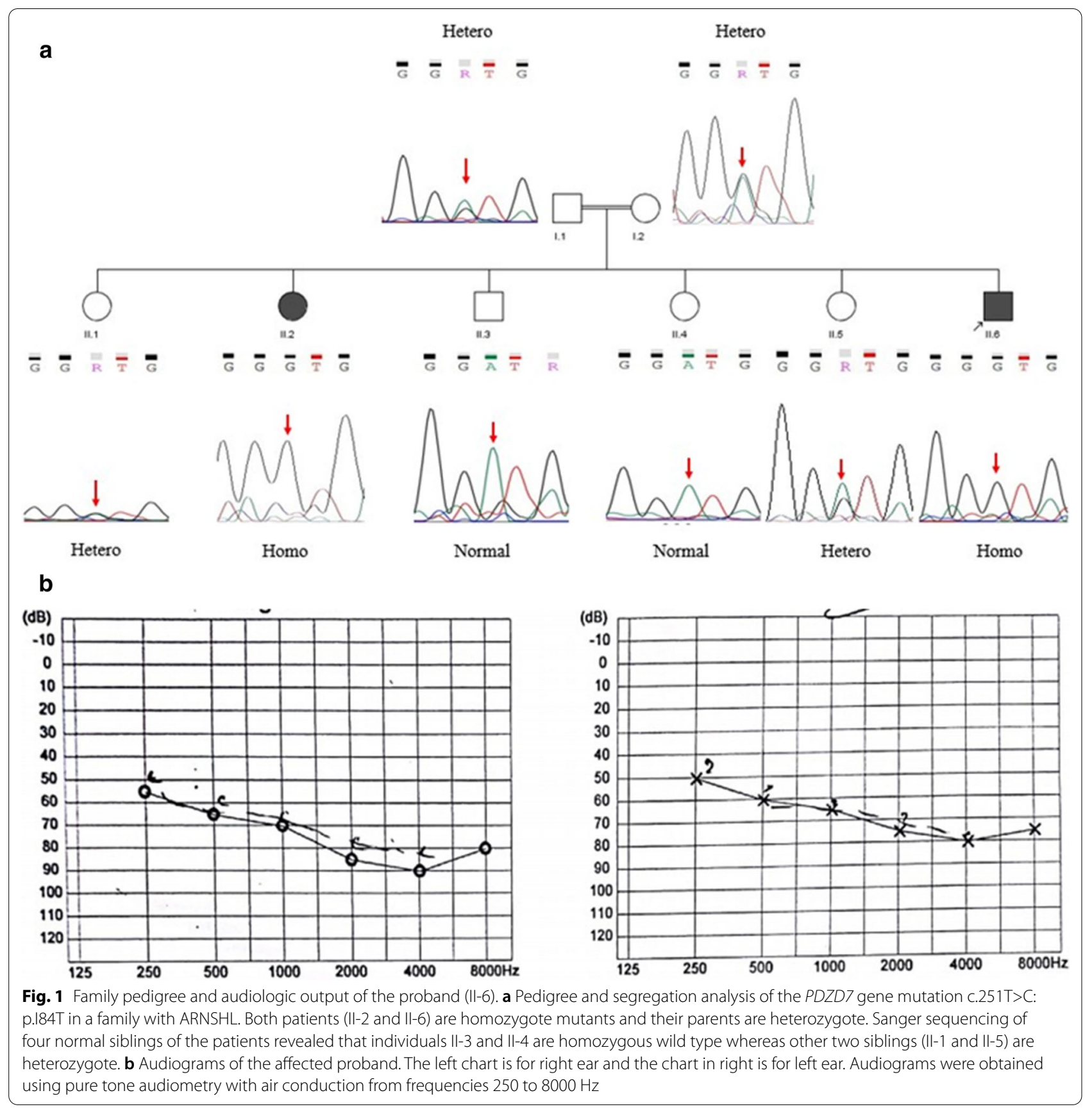

Macaca mulatta, Canis lupus, Bos taurus, Mus musculus, Rattus norvegicus, Gallus gallus, Danio rerio, and Xenopus tropicalis species using Clustal Omega online software. Furthermore, structural 3D models for PDZ1 domain in the PDZD7 protein were constructed based on homology modeling and by using SWISS-MODEL server (https://swissmodel.expasy.org) and were viewed using PyMOL program.

\section{Sanger sequencing and segregation analysis}

To confirm the novel mutation found in the PDZD7 gene, PCR and Sanger sequencing were performed for both patients and their normal family members using following primers: F-5 $5^{\prime}$ TCCCTGACAGCAGCATCC $3^{\prime}$ and R$5^{\prime}$ GCCTTAGAAATGGGCTGACCTG 3' (PCR product: $385 \mathrm{bp}$ ). Finally, the sequencing data was analyzed using Chromas software. 


\section{Results}

Regarding to proband (patient II-6) who was negative for GJB2 and GJB6 genes mutations, he was investigated by TES technique. A novel homozygous missense mutation was identified in exon3 of the PDZD7 gene (NM_001195263); chr10:101024044A/G: $\quad$ c.251T $>$ C: p.I84T. Our review of public databases and the local population database didn't identify any previous reports of the mutation found. Additionally, none of 90 screened healthy controls showed this mutation confirming the novelty of the mutation found. This point mutation results in replacement of a threonine instead of isoleucine 84 in PDZD7 protein. Furthermore, the Sanger sequencing confirmed the mutation found and co-segregated with autosomal recessive inheritance pattern of NSHL disorder (Fig. 1). As expected, affected sister (II-2) had the identified mutation in the PDZD7 gene and unaffected parents (I.1 and I.2 in pedigree) of the proband were heterozygous carriers. Additionally, segregation analysis showed that two normal siblings (II-3 and II-4) of the patients were homozygous wild type whereas other two normal siblings (II-1 and II-5) were heterozygous for the missense mutation c.251T >C: p.I84T of $P D Z D 7$ gene. The corresponding family pedigree and the results of
Sanger sequencing are illustrated in Fig. 1. With respect to audiological and ophthalmic evaluations, while the ophthalmic exams of two studied HL patients were normal (Fig. 2), their pure tone audiometry at $250-8000 \mathrm{~Hz}$, showed severe down sloping hearing loss (Fig. 1).

Furthermore, we performed in-silico analyses for the identified missense mutation, and it was predicted to be "Deleterious" by PROVEAN, SIFT, Polyphen, and Mutation Taster (Table 1). These data revealed that this novel mutation could be cause of deafness in this family. As depicted in Fig. 3a, PDZD7 comprised of four conserved domains (three PDZ domains and one harmonin-Nlike domain (HNLD)) [4]. The results of multiple alignment for the corresponding sequence revealed that the c. $251 \mathrm{~T}>\mathrm{C}$ (p.I84T) occurs at highly conserved residues in PDZ1 (Fig. 3b).

In order to determine how the novel p.I84T mutation affects the conformation of PDZD7, 3D structural models of both wild type and mutant PDZD7 were constructed by SWISS-MODEL. The sequence identity between the target and template was $23.79 \%$. The predicted models covered the target sequence of PDZD7 (1-293) and were viewed with PDB viewer software (PyMol). Since isoleucine is a non-polar amino acid whereas threonine

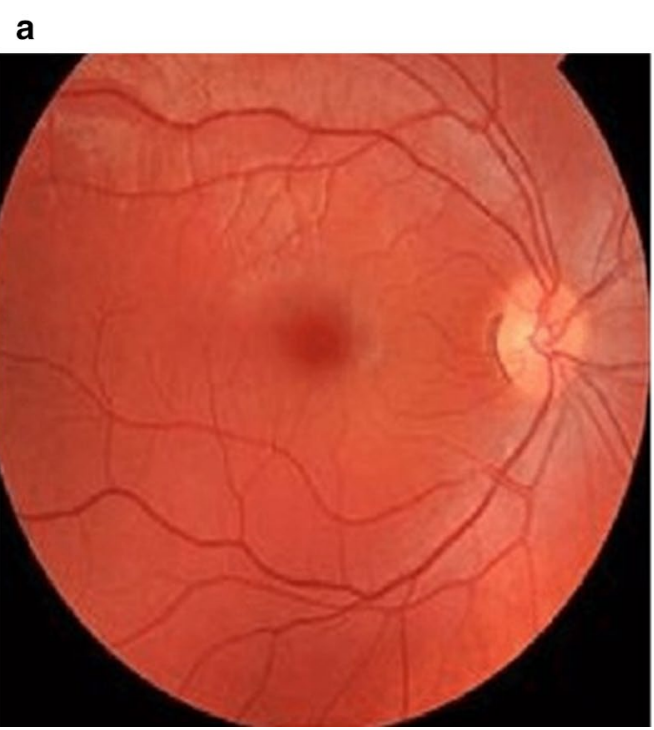

b

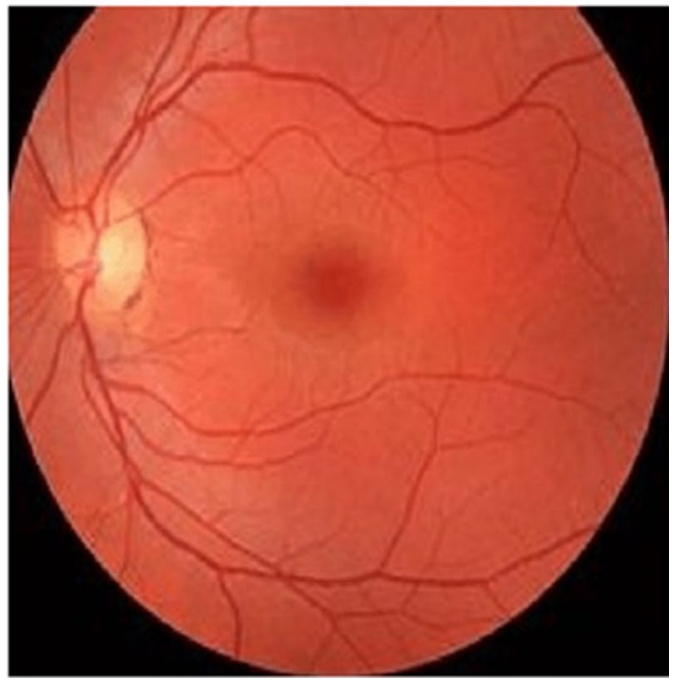

Fig. 2 Image of the normal fundus of the proband's right (a) and left (b) eyes

Table 1 Prediction of pathogenicity of the homozygous mutation c.251T >C in the PDZD7 gene

\begin{tabular}{lllllllll}
\hline $\begin{array}{l}\text { Gene } \\
\text { (RefSeq) }\end{array}$ & Mutation & PROVEAN & SIFT & Polyphen & Mutation Taster & Mutation Assessor & CAAD-Phred & Phenotype \\
\hline $\begin{array}{l}\text { PDZD7 } \\
\text { (NM_001195263) }\end{array}$ & $\begin{array}{l}\text { C.251T }>\text { C } \\
(\text { I84T) }\end{array}$ & D & D & D & D & $L$ & 19.25 & ARNSHL \\
\hline
\end{tabular}

$\mathrm{D}$, damaging; L, low pathogenicity; $\mathrm{ARNSHL}$, autosomal recessive non-syndromic hearing loss 
a

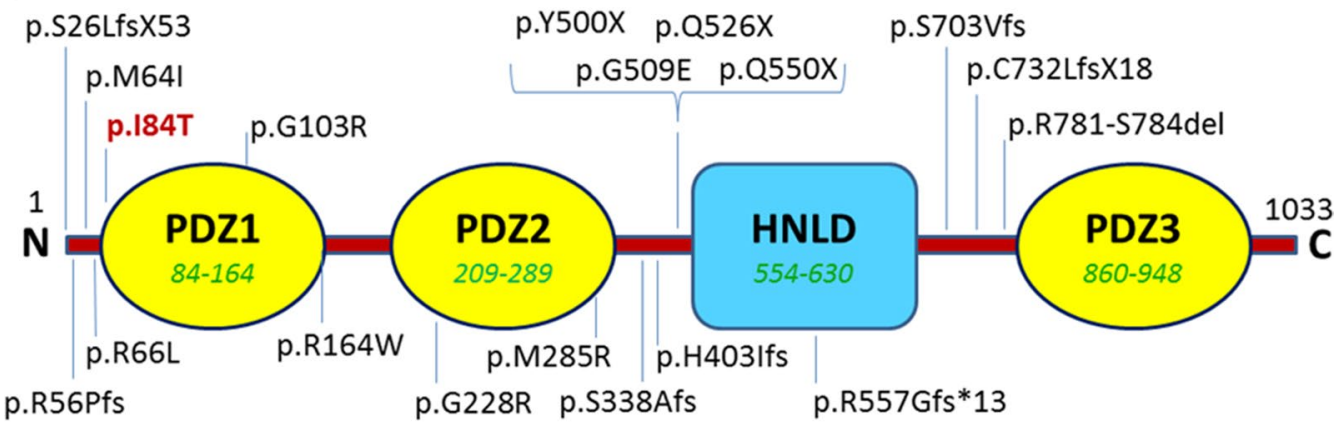

b

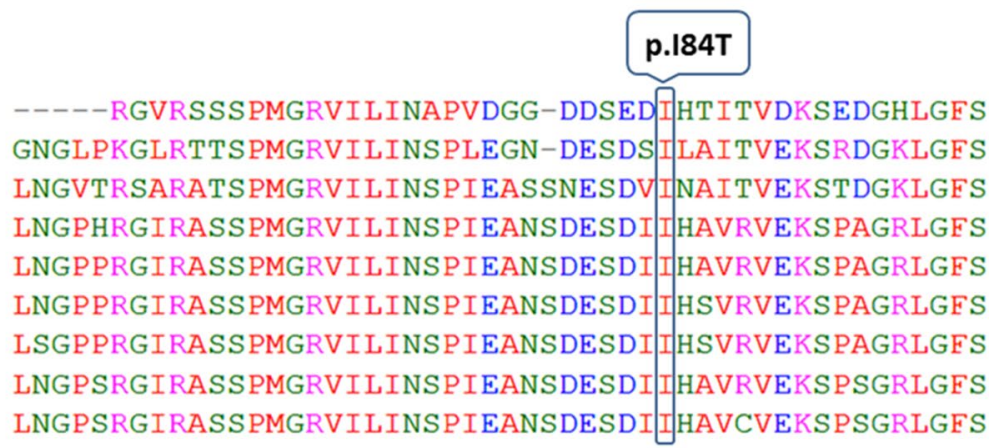

Fig. 3 A schematic representation of the PDZD7 protein domains and the identified mutation p.184T. a PDZD7 comprised of three conserved PDZ domains (yellow) and one HNLD domain (blue). All previously reported PDZD7mutations are shown and the new reported mutation is depicted in red. $\mathbf{b}$ Multiple alignment of PDZD7 protein sequence shows that the lle residue at situation 84 is highly conserved across nine species

is a polar amino acid, it was predicted that substitution of isoleucine to threonine at position 84, possibly perturbing the non-covalent interactions between residues and resulted in formation of a truncated alpha-helix in mutant PDZD7 protein (Fig. 4).

\section{Discussion}

The PDZD7 gene is highly conserved in human, Rhesus monkey, dog, cow, rat, chicken, zebrafish, and frog (https://www.ncbi.nlm.nih.gov/homologene/129509). This gene comprised of 17 exons which encodes a large

\section{a}

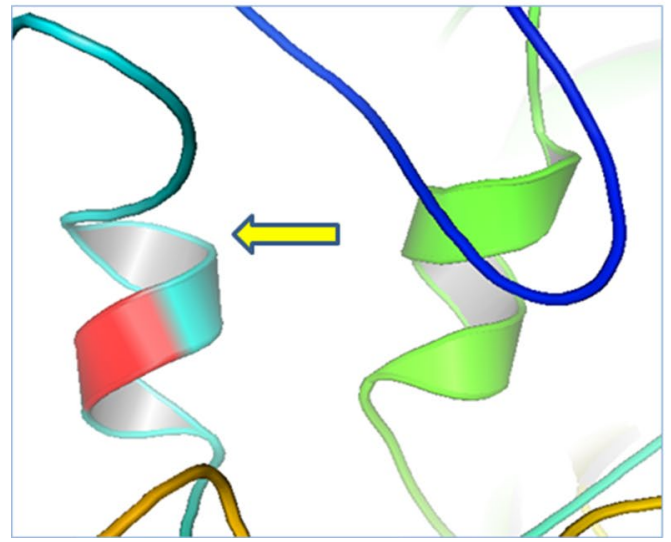

b

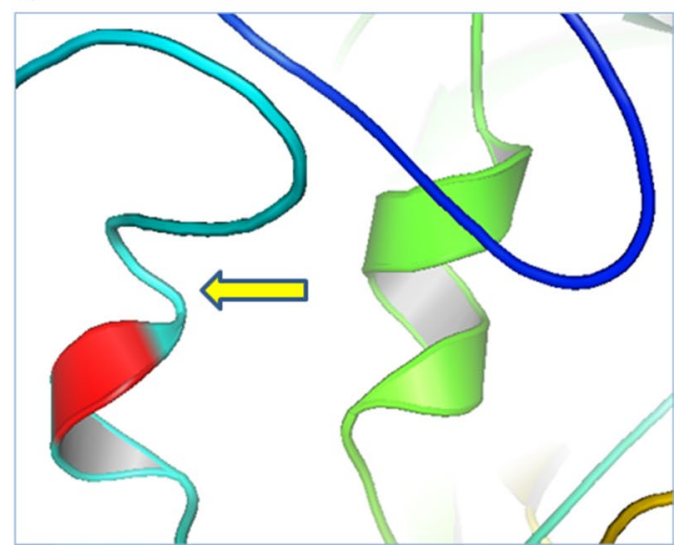

Fig. 4 A schematic representation of PDZD7 and structural analysis of the normal and mutant variants. The 3D structural models were constructed by SWISS-MoDEL and viewed with PyMol software. As it is locally zoomed (at 12 Angstrom) the position of mutation (residue 84 that highlighted in red) makes a complete round of alpha-helix structure in normal protein (a). As shown by a yellow arrow, substitution of isoleucine to threonine at position 84 resulted in formation of a truncated alpha-helix in mutant PDZD7 protein (b) 
scaffold protein named PDZD7. As previously mentioned, the $P D Z D 7$ is expressed in retinal photoreceptors and inner ear hair cells $[4,13]$. Along with other proteins such as WHRN, USH2A, and GPR98, PDZD7 play a critical role in formation of USH2 quaternary complex which is important in normal development and proper function of both auditory and visual systems [4]. Abnormal expression of the $P d z d 7$ gene results in improper organization of hair bundles in mice which can lead to hearing loss [13].

To date, 22 different mutations of the PDZD7 gene have been reported in patients with ARNSHR from Iran, Pakistan, Germany, Korea, Canada, and China. The type of these mutations and the resulted phenotypes are summarized in Table 2. Of course, the PDZD7 gene was originally reported as being responsible for non-syndromic congenital sensori-neural hearing loss in a 9-year-old German boy due to a reciprocal translocation $\mathrm{t}(10 ; 11)$ (q24.3;q23.3) [16]. Affected siblings of the present study shows bilaterally symmetrical severe down sloping ARNSHL. The next generation sequencing using TES was identified a novel homozygous mutation c.251T>C: p.I84T of PDZD7 gene. Furthermore, segregation analysis determined that this substitution of threonine to Isoleucine at highly conserved position 84 is causative (Fig. 1) and affects the function of protein deleteriously. This mutation is located in the PDZ1 domain (Fig. 3). It has been previously documented that PDZ1 domain plays a critical role in interaction of PDZD7 with cytoplasmic part of USH2A protein [4]. Therefore, the novel p.I84T mutation may interrupt normal interaction between PDZD7 and USH2A. As recently reported, PDZD7-binding proteins, such as ADGRV1, gelsolin, and $\beta$-catenin, play significant roles in hearing. PDZD7 interacts with these proteins via domains PDZ1/PDZ2 [22]. On the other hands, in-silico analysis of normal and mutant PDZD7 protein models revealed that isoleucine substitution with threonine may results in formation of a truncated alpha-helix in mutant PDZD7 (Fig. 4). Although in silico analysis of the mutant protein is a reliable prediction tool for structural impacts of missense mutations, more experimental evaluations are actually needed to completely determine the consequences of the detected

Table 2 Summary of the all reported PDZD7 mutations and associated phenotypes to date

\begin{tabular}{|c|c|c|c|c|c|c|}
\hline Nucleotide change & Consequence & Genotype & The affected Domain & Phenotype & Family origin & References \\
\hline c.166_167insC & p.R56Pfs X24 & Hetero & - & USH2 & Canadian & {$[5]$} \\
\hline c. $1750-2 A>G$ & Splice site & Hetero & $\mathrm{HNL}$ & & German & \\
\hline c.2194_2203del & p.C732LfsX18 & Hetero & - & & & \\
\hline c.76_77del & p.S26LfsX53 & Hetero & - & $\mathrm{HL}$ & Korean & {$[23]$} \\
\hline c.307G >C & p.G103R & Homo & PDZ1 & ARNSHL & Iranian & [12] \\
\hline c. $682 \mathrm{G}>\mathrm{A}$ & p.G228R & Homo & PDZ2 & & & \\
\hline C. $1576 C>T$ & p.Q526X & Homo & - & & & \\
\hline $\begin{array}{l}\text { c. } 854 T>G \\
\text { c. } 1500 C>A\end{array}$ & $\begin{array}{l}\text { p.M285R } \\
\text { p.Y500X }\end{array}$ & Comp Het & $\begin{array}{l}\text { PDZ2 } \\
-\end{array}$ & & & \\
\hline $\begin{array}{l}\text { c.1648C }>\text { T } \\
\text { c.2107delA }\end{array}$ & $\begin{array}{l}\text { p.Q550X } \\
\text { p.S703Vfs }\end{array}$ & Comp Het & - & ARNSHL & German & {$[15]$} \\
\hline $\begin{array}{l}\text { c. } 226+2 \_226+ \\
\text { 5delTAGG }\end{array}$ & $\begin{array}{l}\text { Abolished splicing in } \\
\text { exon 2-intron } 2 \\
\text { junction }\end{array}$ & Homo & - & ARNSHL & Pakistani & {$[24]$} \\
\hline c.197G $>\mathrm{T}$ & p.R66L & Homo & - & ARNSHL & Chinese & [14] \\
\hline $\begin{array}{l}\text { c.1207delC } \\
\text { c.166-167ins } C^{a}\end{array}$ & $\begin{array}{l}\text { p.H403lfs } \\
\text { p.R56Pfs }\end{array}$ & Comp Het & - & & & \\
\hline c.1012delA & p.S338Afs & - & - & $\begin{array}{l}\text { Usher syn- } \\
\text { drome, type } \\
\text { 2A }\end{array}$ & - & ClinVar ID: 560723 \\
\hline $\begin{array}{l}\text { c. } 192 \mathrm{G}>\mathrm{A} \\
\text { c.1648C }>\mathrm{T} \\
\text { c. } 2341 \_2352 \mathrm{del}\end{array}$ & $\begin{array}{l}\text { p.M64l } \\
\text { p.Q550X } \\
\text { p.R781-S784del }\end{array}$ & Comp Het & - & ARNSHL & Chinese & {$[25]$} \\
\hline $\begin{array}{l}\text { c. } 490 \mathrm{C}>\mathrm{T} \\
\text { c. } 1669 \mathrm{delC} \\
\text { c. } 1526 \mathrm{G}>\mathrm{A}\end{array}$ & $\begin{array}{l}\text { p.R164W } \\
\text { p.R557Gfs*13 } \\
\text { p.G509E }\end{array}$ & Homo/Comp Het & PDZ1 and HNLD & ARNSHL & Korean & {$[26]$} \\
\hline C. $251 \mathrm{~T}>\mathrm{C}$ & p.184T & Homo & PDZ1 & ARNSHL & Iranian & This report \\
\hline
\end{tabular}

The first reported mutation in PDZD7 was detected by Schneider et al. as a consequence of a homozygous reciprocal translocation, $t(10 ; 11)[16]$

a This frame-shift mutation was originally reported by Eberman et al. (5) 
mutation on expression and function of the corresponding gene and protein.

Although, the gene encoding PDZD7 protein was originally defined as a modifier of retinal disease and a contributor for Usher syndrome $[5,16]$, but this interpretation was revised according to the recent studies $[12,14]$. In accordance with this recent study, mutation in PDZD7 may results in NSHL without any RP manifestations. It could be because of compensatory effects of other scaffolding proteins involved in retina function [12].

\section{Conclusions}

Overally, this report supports the contribution of $P D Z D 7$ bi-allelic mutations to the etiology of ARNSHL in mankind and extends the mutations spectrum of the PDZD7 gene in Iranian population and also worldwide. Additionally, this research is considerable because it leads to a better understanding of $P D Z D 7$ recessive mutations on phenotypic outcome and strengthens the clinical importance of this gene in ARNSHL patients.

\section{Supplementary Information}

The online version contains supplementary material available at https://doi. org/10.1186/s12920-021-00884-4.

Additional file 1. The list of analyzed genes involved in Hearing impairment.

\section{Abbreviations}

ARNSHL: autosomal recessive non-syndromic hearing loss; $\mathrm{HL}$ : hearing loss; GJB2: gap junction beta-2 protein; GJB6: gap junction beta 6 protein; TES: targeted exome sequencing; PDZD7: PDZ domain-containing 7; USH: Usher syndrome; RP: retinitis pigmentosa; USH2: Usher syndrome type 2; HNLD: harmonin-N-like domain.

\section{Acknowledgement}

We are so grateful to patients and their respected families who kindly consented to join the study. We thank Dr. Masoumeh Heshmati and Dr. Nooshin Barikrow (from Pharmaceutical Sciences Research Center, Tehran medical Sciences, Islamic Azad University, Tehran, Iran) and Dr. Elham Abdi (Kosar Hospital, Semnan University of Medical Sciences, Semnan, Iran) for technical collaborations, as well.

\section{Authors' contributions}

HF, performed data analysis, literature review and drafted the manuscript. SB, and SN, performed experimental assays; FP, organized this study, performed data analysis, reviewed clinical and laboratory data, and finalized this manuscript. All authors read and approved the final manuscript.

\section{Funding}

Not applicable.

\section{Availability of data and materials}

The datasets generated and/or analysed during the current study have uploaded in the NCBI dbVar repository (https://www.ncbi.nlm.nih.gov/ clinvar/variation/992657/). The direct web links to the GenBank reference sequence NM_001195263 (https://www.ncbi.nlm.nih.gov/nuccore/NM_00119 5263.1) and its orthologs from Macaca mulatta (https://www.ncbi.nlm.nih. gov/nucleotide/XM_015148033.2? report=genbank\&log\$=nucltop\&blast _rank=12\&RID=Z9R3J22J013), Canis lupus (https://www.ncbi.nlm.nih.
gov/nucleotide/XM_035707965.1?report=genbank\&log\$=nucltop\&blast _rank=65\&RID=Z9R3J22J013), Bos taurus (https://www.ncbi.nlm.nih.gov/ nuccore/XM_005225682.4), Mus musculus (https://www.ncbi.nlm.nih.gov/ nuccore/NM_001195265.1), Rattus norvegicus (https://www.ncbi.nlm.nih. gov/nuccore/XM_006231449.3), Gallus gallus (https://www.ncbi.nlm.nih.gov/ nuccore/XM_015288750.2), Danio rerio (https://www.ncbi.nlm.nih.gov/nucco re/NM_001190757.1), and Xenopus tropicalis (https://www.ncbi.nlm.nih.gov/ nuccore/XM_031906428.1) species are all available.

\section{Consent for publication}

Written informed consent for publication was obtained from the all of the participants and the parents of the minors.

\section{Ethics approval and consent to participate}

This research had been approved by the ethics committee of the pharmaceutical sciences branch of Islamic Azad University, Tehran, Iran (ethics approval code no. IR.IAU.PS.REC.1396.91). Written informed consent was obtained from all participants and legal guardians to take part in this study. A copy of the written consent is available for review by the Editor of this journal.

\section{Competing interests}

The authors declare that they have no conflicts of interest.

\section{Author details}

${ }^{1}$ Department of Genetics, Faculty of Advanced Science and Technology, Tehran Medical Sciences, Islamic Azad University, Tehran, Iran. ${ }^{2}$ Pharmaceutical Sciences Research Center, Tehran Medical Sciences, Islamic Azad University, Tehran, Iran. ${ }^{3}$ Department of Biology, Faculty of Basic Sciences, Semnan University, Semnan 35131-19111, Iran.

Received: 4 December 2020 Accepted: 25 January 2021

Published online: 02 February 2021

\section{References}

1. Morton CC, Nance WE. Newborn hearing screening — a silent revolution. N Engl J Med. 2006;354(20):2151-64.

2. Ebermann I, Phillips JB, Liebau MC, Koenekoop RK, Schermer B, Lopez I, et al. PDZD7 is a modifier of retinal disease and a contributor to digenic Usher syndrome. J Clin Investig. 2011;121(2):821.

3. Liu H, Pecka JL, Zhang Q, Soukup GA, Beisel KW, He DZ. Characterization of transcriptomes of cochlear inner and outer hair cells. J Neurosci. 2014;34(33):11085-95.

4. Chen Q, Zou J, Shen Z, Zhang W, Yang J. Whirlin and PDZ domain containing 7 (PDZD7) proteins are both required to form the quaternary protein complex associated with Usher syndrome type 2. J Biol Chem. 2014:jbc. M114. 610535

5. Ebermann I, Phillips JB, Liebau MC, Koenekoop RK, Schermer B, Lopez I, et al. PDZD7 is a modifier of retinal disease and a contributor to digenic Usher syndrome. J Clin Investig. 2010;120(6):1812-23.

6. Grati Mh, Shin J-B, Weston MD, Green J, Bhat MA, Gillespie PG, et al. Localization of PDZD7 to the stereocilia ankle-link associates this scaffolding protein with the Usher syndrome protein network. J Neurosci. 2012;32(41):14288-93.

7. Hu Q-X, Dong J-H, Du H-B, Zhang D-L, Ren H-Z, Ma M-L, et al. Constitutive Gai coupling activity of very large G protein-coupled receptor 1 (VLGR1) and its regulation by PDZD7 protein. J Biol Chem. 2014;289(35):24215-25.

8. Adato A, Lefevre G, Delprat B, Michel V, Michalski N, Chardenoux S, et al. Usherin, the defective protein in Usher syndrome type IIA, is likely to be a component of interstereocilia ankle links in the inner ear sensory cells. Hum Mol Genet. 2005;14(24):3921-32.

9. Sandberg MA, Rosner B, Weigel-DiFranco C, McGee TL, Dryja TP, Berson EL. Disease course in patients with autosomal recessive retinitis pigmentosa due to the USH2A gene. Invest Ophthalmol Vis Sci. 2008;49(12):5532-9.

10. McGee TL, Seyedahmadi BJ, Sweeney MO, Dryja TP, Berson EL. Novel mutations in the long isoform of the USH2A gene in patients with Usher syndrome type II or non-syndromic retinitis pigmentosa. J Med Genet. 2010;47(7):499-506. 
11. Sadeghi AM, Cohn ES, Kimberling WJ, Halvarsson G, Möller C. Expressivity of hearing loss in cases with Usher syndrome type IIA. Int J Audiol. 2013;52(12):832-7.

12. Booth KT, Azaiez H, Kahrizi K, Simpson AC, Tollefson WT, Sloan CM, et al. PDZD7 and hearing loss: more than just a modifier. Am J Med Genet A. 2015;167(12):2957-65.

13. Zou J, Zheng T, Ren C, Askew C, Liu X-P, Pan B, et al. Deletion of PDZD7 disrupts the Usher syndrome type 2 protein complex in cochlear hair cells and causes hearing loss in mice. Hum Mol Genet. 2013;23(9):2374-90.

14. Guan J, Wang H, Lan L, Wang L, Yang J, Xie L, et al. Novel recessive PDZD7 biallelic mutations in two Chinese families with non-syndromic hearing loss. Am J Med Genet A. 2018;176(1):99-106.

15. Vona B, Lechno S, Hofrichter MA, Hopf S, Läßig AK, HaafT, et al. Confirmation of PDZD7 as a nonsyndromic hearing loss gene. Ear Hear. 2016;37(4):e238-46

16. Schneider E, Märker T, Daser A, Frey-Mahn G, Beyer V, Farcas R, et al. Homozygous disruption of PDZD7 by reciprocal translocation in a consanguineous family: a new member of the Usher syndrome protein interactome causing congenital hearing impairment. Hum Mol Genet. 2008;18(4):655-66.

17. Noavar S, Behroozi S, Tatarcheh T, Parvini F, Foroutan M, Fahimi H. A novel homozygous frame-shift mutation in the SLC29A3 gene: a new case report and review of literature. BMC Med Genet. 2019;20(1):147.

18. Karimi AH, Karimi MR, Farnia P, Parvini F, Foroutan M. A homozygous truncating mutation in NALCN causing IHPRF1: detailed clinical manifestations and a review of literature. Appl Clin Genet. 2020;13:151.

19. McKenna A, Hanna M, Banks E, Sivachenko A, Cibulskis K, Kernytsky A, et al. The genome analysis toolkit: a MapReduce framework for analyzing next-generation DNA sequencing data. Genome Res. 2010;20(9):1297-303.

20. Li H, Durbin R. Fast and accurate short read alignment with BurrowsWheeler transform. bioinformatics. 2009;25(14):1754-60.

21. Wang K, Li M, Hakonarson H. ANNOVAR: functional annotation of genetic variants from high-throughput sequencing data. Nucleic Acids Res. 2010;38(16):164.

22. Du H, Ren $R$, Chen P, Xu Z, Wang Y. Identification of binding partners of deafness-related protein PDZD7. Neural Plasticity. 2018.

23. Kim NK, Kim AR, Park KT, Kim SY, Kim MY, Nam J-Y, et al. Whole-exome sequencing reveals diverse modes of inheritance in sporadic mild to moderate sensorineural hearing loss in a pediatric population. Genet Med. 2015;17(11):901

24. Stabej PLQ, James C, Ocaka L, Tekman M, Grunewald S, Clement E, et al. An example of the utility of genomic analysis for fast and accurate clinical diagnosis of complex rare phenotypes. Orphanet J Rare Diseases. 2017;12(1):24.

25. Luo H, Hassan RN, Yan J, Xie J, Du P, Hu Q, et al. Novel recessive PDZD7 biallelic mutations associated with hereditary hearing loss in a Chinese pedigree. Gene. 2019;709:65-74.

26. Lee S-Y, Han JH, Kim BJ, Oh SH, Lee S, Oh D-Y, et al. Identification of a Potential Founder Effect of a Novel PDZD7 Variant Involved in Moderate-to-Severe Sensorineural Hearing Loss in Koreans. Int J Mol Sci. 2019;20(17):4174.

\section{Publisher's Note}

Springer Nature remains neutral with regard to jurisdictional claims in published maps and institutional affiliations.
Ready to submit your research? Choose BMC and benefit from:

- fast, convenient online submission

- thorough peer review by experienced researchers in your field

- rapid publication on acceptance

- support for research data, including large and complex data types

- gold Open Access which fosters wider collaboration and increased citations

- maximum visibility for your research: over $100 \mathrm{M}$ website views per year

At BMC, research is always in progress.

Learn more biomedcentral.com/submissions 